\title{
Research on combustion performance of PVC foam in fire propagation apparatus
}

\author{
Guoan Zhang ${ }^{1}$, Lingling Wei ${ }^{1}$, Junhao Gao ${ }^{2}$, Tingting $\mathrm{Qiu}^{2}$, Rongnan Yuan ${ }^{2}$, and Shouxiang $\mathrm{Lu}^{2 *}$ \\ ${ }^{1}$ CRRC Qingdao Sifang CO., LTD, Qingdao 266111, China \\ ${ }^{2}$ State Key Laboratory of Fire Science, University of Science and Technology of China, Hefei, 230026, China
}

\begin{abstract}
Polyvinyl chloride foam (PVC) is widely used as the wall materials of the high-speed train. The combustion characteristics of PVC foam under the heat fluxes of $20-60 \mathrm{~kW} / \mathrm{m}^{2}$ are investigated by fire Propagation Apparatus (FPA). The results show that the ignition time of PVC foam decreases with the increase of heat flux. The peak of heat release rate, mass loss rate and smoke production rate increase with the increase of heat flux. Under the condition of $60 \mathrm{~kW} / \mathrm{m}^{2}$, the heat release rate has the peak value of $109.10 \mathrm{~kW} / \mathrm{m}^{2}$. The research on the combustion characteristics of the PVC can be used to analyse the fire risk of the train and guide the formulation of safety measures.
\end{abstract}

\section{Introduction}

Polyvinyl chloride foam (PVC) has been one of the most important industrial materials due to its good mechanical properties. In high-speed train, PVC is often used as the wall material. It is also widely used as part of the wall materials of building and composite sandwich materials in the marine industry 1 . Many scholars have done a lot of research on PVC foam. Zhou 2 experimentally studied the performance of PVC foam as core sandwich under air blast loading. In addition, Ding 1 investigated the degradation of sandwich composites involving two vinylester composite skins bonded to PVC foam core in the marine environment. To improve the mechanical properties of PVC foam, some scholars change the chemical structure of the PVC, Jiang 3 and Zhang 4 have studied the crosslinked PVC foams.

Although there have been a lot of researches on the mechanical properties of PVC foam, there are few studies on its combustion characteristics. Since PVC foam has been widely used in high-speed train materials, the fire hazard of PVC need to be quantitatively evaluated.

In this paper, PVC foam was studied by fire propagation apparatus (FPA). In order to simulate different fire conditions, the research investigated the heat release rate, mass loss rate and smoke production rate of PVC foam under different heat fluxes of 20, 30, 40 and $60 \mathrm{~kW} / \mathrm{m} 2$. According to the experimental data, the combustion performance is analysed. The main objective is to improve the understanding of combustion characteristics of PVC foam.

\section{Experiments}

\footnotetext{
* Corresponding author: sxlu@ustc.edu.cn
}

\subsection{Materials}

The experimental material is PVC foam, and its main physical properties are shown in Table. 1. The sample size is $100 \mathrm{~mm} \times 100 \mathrm{~mm}$ and the thickness is $18.7 \mathrm{~mm}$. According to ASTM E2058 5, the bottom and sides of the sample are wrapped with aluminum foil. The ceramic fiber cotton is placed between the sample and the bottom aluminum foil, which can prevent heat loss and ensure the accuracy of the experimental results.

Table. 1 Physical properties of PVC foam

\begin{tabular}{ll}
\hline Physical properties & Value \\
\hline Thermal conductivity $(\mathrm{W} /(\mathrm{m} \cdot \mathrm{K}))$ & 0.0364 \\
Specific heat capacity $(\mathrm{J} /(\mathrm{kg} \cdot \mathrm{K}))$ & 1110.9 \\
Density $\left(\mathrm{kg} / \mathrm{m}^{3}\right)$ & 56.98 \\
Oxygen index $(\%)$ & 29 \\
\hline
\end{tabular}

\subsection{Apparatus and experimental methods}

The FPA was used in this paper. The flame diffuser is mainly composed of style combustion chamber, exhaust device, weighing system and gas analysis device. FPA can evaluate the flammability of materials or products. Its main feature is that it has a unique distribution chamber, which can provide a gas atmosphere with controllable oxygen concentration for test samples, and study the combustion performance of materials in poor oxygen atmosphere, normal oxygen atmosphere, or rich oxygen. FPA heater is distributed in a horizontal manner around the material for heating. 
To simulate different fire conditions, heat fluxes of 20, 30, 40 and $60 \mathrm{~kW} / \mathrm{m}^{2}$ were selected. During the experiment, the ambient temperature was $23.4^{\circ} \mathrm{C}$ and the relative humidity was $54 \%$. Once a visible flame is observed, the sample is considered to be ignited after the experiment started. If no visible flame is observed after 900 seconds from the start of the experiment, the experiment can be stopped. Repeat the experiment two times and average it to reduce the experimental error 6 .

\section{Results and discussion}

\subsection{Visual observation}

When the sample is exposed to heat flux, the surface of the sample becomes black and a large amount of pyrolysis gas is released. Once the sample is ignited, a large amount of smoke is produced. At the same time, the sample begins to shrink and the edges are rolled up, accompanied by bubbling. It can be seen from Fig. 1that the sample has the highest degree of shrinkage under the heat flux of $60 \mathrm{~kW} / \mathrm{m}^{2}$, and a large amount of bubbles bulge and break the surface. The smaller the heat flux is, the flatter the surface of the sample is.

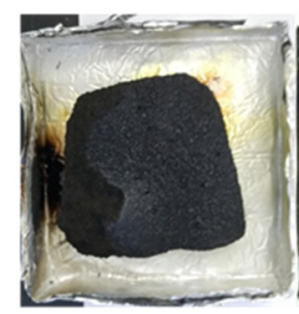

(a) $20 \mathrm{~kW} / \mathrm{m}^{2}$

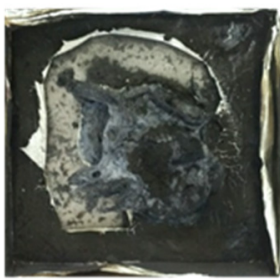

(b) $40 \mathrm{~kW} / \mathrm{m}^{2}$

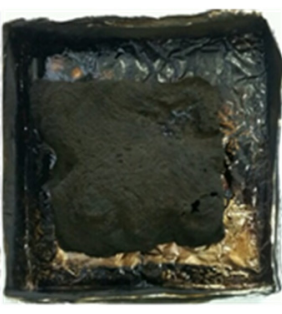

(b) $30 \mathrm{~kW} / \mathrm{m}^{2}$

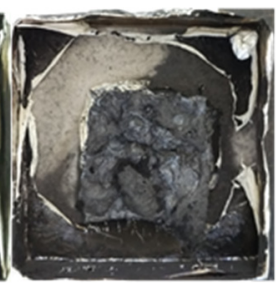

(b) $60 \mathrm{~kW} / \mathrm{m}^{2}$
Fig. 1 Samples after combustion test

\subsection{Ignition time}

The ignition time $\left(t_{i g n}\right)$ is important for characterizing fire hazard and thermal decomposition behavior of materials. The sample with long ignition time has good fire resistance and low fire hazard. The experimental data are listed in Table. 2. It can be seen that the ignition time of PVC foam decreases with the increase of heat flux.

In order to determine the thermal characteristic of the PVC, the method of Janssens 7 is employed in this paper.

According to the Janssens, the transformed ignition time $\left(1 / t_{i g n}\right)^{n}$ is correlated with and the external heat flux $\dot{q}_{\text {ext }}^{\prime \prime}$, where $\mathrm{n}$ is a coefficient, and $\mathrm{n}=0.3,0.5,0.55,1$ in this study. The correlations between the transformed ignition time and the heat flux are presented as follows:

$$
\begin{gathered}
\left(1 / t_{i g n}\right)^{0.3}=0.00445 \dot{q}_{\text {ext }}^{\prime \prime}+0.11226 \\
\left(1 / t_{\text {ign }}\right)^{0.5}=0.00323 \dot{q}_{\text {ext }}^{\prime \prime}+0.00201 \\
\left(1 / t_{\text {ign }}\right)^{0.55}=0.00289 \dot{q}_{\text {ext }}^{\prime \prime}-0.00772 \\
\left(1 / t_{i g n}\right)^{1}=0.00085 \dot{q}_{\text {ext }}^{\prime \prime}-0.01438
\end{gathered}
$$

$\mathrm{R}^{2}$ represents the correlation between the line and discrete points. The value of $n$ with higher $\mathrm{R}^{2}$ shows that the curves are in good agreement with the experimental data. Results are shown in Fig. 2.

Table. 2 PVC foam parameters

Heat flux $\left(\mathrm{kW} / \mathrm{m}^{2}\right)$ Ignition time (s) Peak HRR $\left(\mathrm{kW} / \mathrm{m}^{2}\right)$

\begin{tabular}{lll}
20 & 214.0 & 30.82 \\
30 & 126.5 & 55.95 \\
40 & 49.5 & 90.25 \\
60 & 27.0 & 109.10 \\
\hline
\end{tabular}

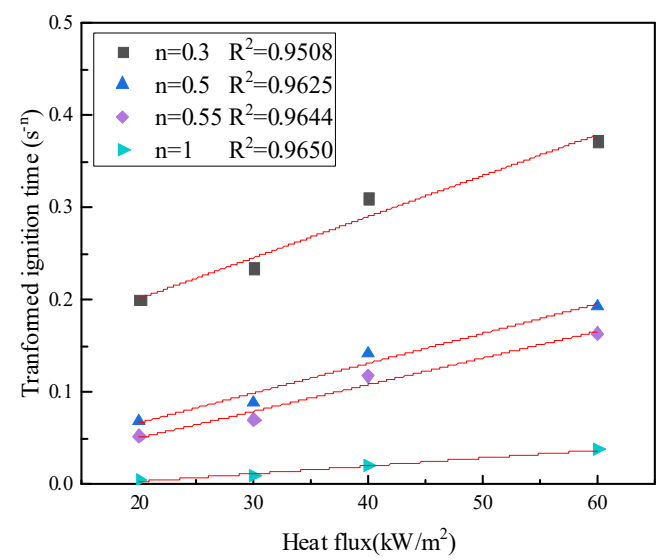

Fig. 2 Correlations between transformed ignition time and heat flux

As shown in Fig. 2, the value of $\mathrm{R}^{2}$ corresponding to the case of $n=1$ is slightly higher than other cases. The results show that $n=1$ is in good agreement with the experimental data, and the ignition time can be well predicted according to the heat flux value by Eqs.4.

\subsection{Heat release rate}


Heat release rate (HRR) refers to an important parameter to characterize the fire intensity of materials and it can be used to estimate the scale of fire 9. The HRR under different heat fluxes are shown in Fig. 3. It can be seen from the figure that the peak value of HRR increases with the increase of heat flux. During the whole combustion, there exists one peak except under 20 $\mathrm{kW} / \mathrm{m}^{2}$. At $20 \mathrm{~kW} / \mathrm{m}^{2}$, a small peak of HRR first appears after the sample is ignited, and then the flame decreases. With the continuous pyrolysis of the bottom sample, the lower sample starts to burn, and the second peak of HRR appears. However, when the heat flux is greater than 20 $\mathrm{kW} / \mathrm{m}^{2}$, the pyrolysis rate of the material is relatively great, and the sample burns vigorously after being ignited. Therefore, only a peak of HRR appears.

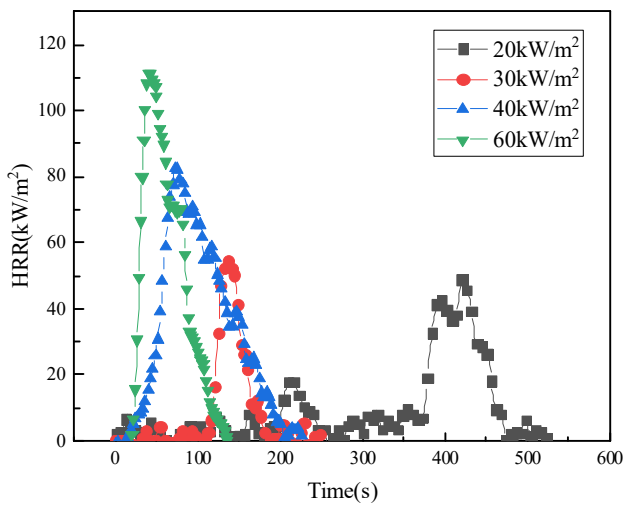

Fig. 3 HRR under different heat fluxes

\subsection{Mass loss and Mass loss rate}

Mass loss can effectively represent the thermal decomposition process of materials 10 , which is usually expressed by the fraction of residual mass and initial mass.

$$
\phi=\frac{m}{m_{0}}
$$

where, $\phi$ is the fraction of residual mass and initial mass, $\mathrm{m}$ denotes the residual mass, and $\mathrm{m}_{0}$ denote the initial mass. Evolution of mass loss under different heat fluxes are shown in Fig. 4.

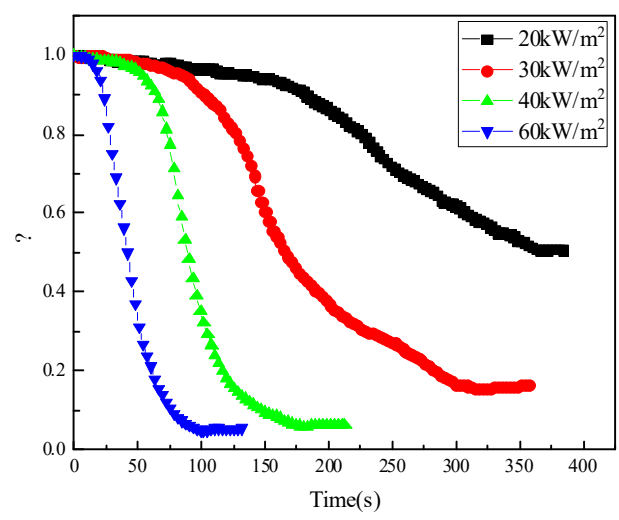

Fig. 4 Fraction of the residual mass and initial mass under different heat fluxes

As shown in Fig. 4, the residual mass gradually decreases with the progress of combustion, and the higher the heat flux is, the smaller the remained mass is. Comparing the $\phi$ under 20 and $60 \mathrm{~kW} / \mathrm{m}^{2}, \phi$ under 60 $\mathrm{kW} / \mathrm{m}^{2}$ decreased by $45.5 \%$.

Mass loss rate (MLR) is defined as the mass loss rate of evaporation and combustion of solid or liquid fuels 11 . The MLR under different heat fluxes is shown in Fig. 5. As can be seen, the evolution of the MLR curves are dependant of the heat flux. The higher the heat flux, the shorter time to peak MLR, and the wider the peak amplitude. The MLR fluctuates greatly over time, but there is still a peak throughout the period. The comparison between the peak value of MLR position and HRR curve shows good consistency, and HRR is in good synchronism with the peak value of MLR. The MLR represents the intensity of combustion, thus the higher the MLR is, the more intense the combustion process is, and the higher the HRR is. It is found that the peak value of MLR increases with the increase of heat flux density. The higher the heat flux is, the higher the peak HRR is, and thus the corresponding peak MLR is higher.

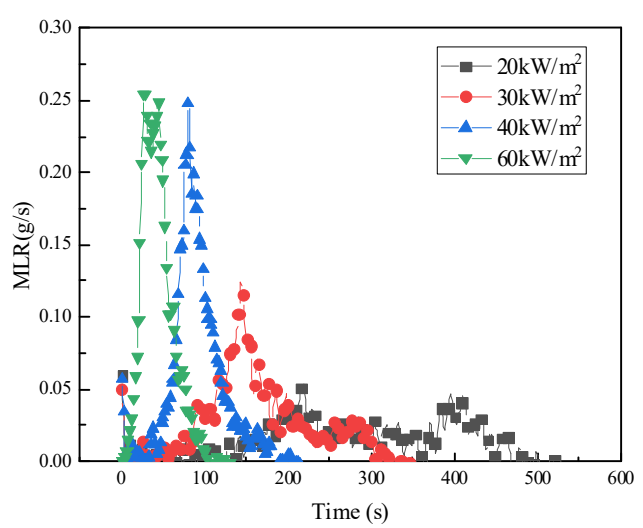

Fig. 5 Mass loss rate under different heat fluxes 
The main causes of casualties in fire are smoke and poisonous gases. In this paper, $\mathrm{CO}$ and $\mathrm{CO}_{2}$ yield are measured, and the results are shown in Table. 3. The results show that $\mathrm{CO}$ and $\mathrm{CO}_{2}$ yield are related to heat flux, and tend to decrease with the increase of heat flux.

Table. $3 \mathrm{CO}$ and $\mathrm{CO}_{2}$ yield

\begin{tabular}{cllll}
\hline Heat flux $\left(\mathrm{kW} / \mathrm{m}^{2}\right)$ & 20 & 30 & 40 & 60 \\
\hline$y_{\mathrm{CO}}$ & 0.152 & 0.094 & 0.062 & 0.033 \\
$y_{\mathrm{CO}_{2}}$ & 4.926 & 3.137 & 1.252 & 0.869 \\
\hline
\end{tabular}

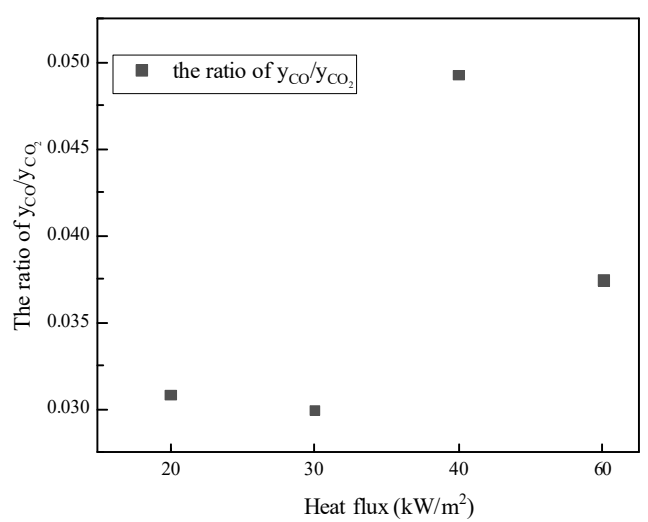

Fig. 6 The ratio of $\mathrm{yco}_{\mathrm{CO}} \mathrm{y}_{\mathrm{CO} 2}$ under different heat fluxes

Fig. 6 shows the ratio of $\mathrm{y}_{\mathrm{CO}} / \mathrm{y}_{\mathrm{CO} 2}$ under different heat fluxes. It is observed that the maximum of the ratio of $\mathrm{y}_{\mathrm{CO}} / \mathrm{y}_{\mathrm{CO} 2}$ is 0.037 when the heat flux is $40 \mathrm{~kW} / \mathrm{m}^{2}$.

\subsection{Fire growth index}

The Fire Growth Index (FGI) is the ratio of the peak HRR to the ignition time and it can be used to evaluate the risk of flashover [12]. The higher peak HRR and the shorter ignition time can both result in the higher FGI. Table. 2 shows the measured parameters of PVC foam under different heat fluxes.

According to Table. 2, FGI values of each heat flux can be calculated. As presented in Fig. 7, FGI increases with the increase of heat flux, thus the probability of flashover increases. When the heat flux is $60 \mathrm{~kW} / \mathrm{m}^{2}$, the FGI value is the largest and the fire hazard is the greatest.

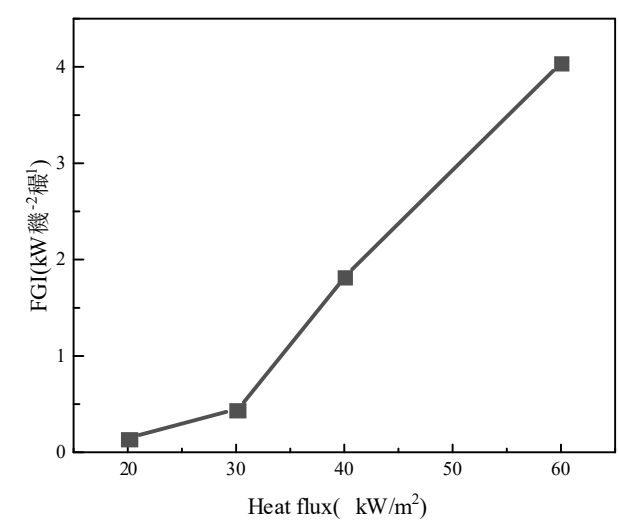

Fig. 7 FGI under different heat fluxes

\section{Conclusion}

In this paper, the combustion characteristics of PVC have been investigated by FPA under different heat fluxes. According to the data, the following conclusions can be drawn: (1) With the increase of heat flux, the ignition time of PVC foam decreases. The ignition time can be well predicted according to the heat flux value by Eqs.4. (2) The peak value of HRR increases with the increase of heat flux. (3) The fraction of residual mass decreases with the increase of heat flux. In addition, the peak value of MLR tends to increase, and the time corresponding to the peak value is in good consistency with the peak value of HRR. (4) With the increase of heat flux, $\mathrm{CO}$ and $\mathrm{CO}_{2}$ yield decrease. When the heat flux is $40 \mathrm{~kW} / \mathrm{m}^{2}$, the ratio of $\mathrm{y}_{\mathrm{CO}} / \mathrm{y}_{\mathrm{CO} 2}$ is largest and the value is 0.037 . (5) The value of FGI increases when the heat flux increases, increasing the probability of flashover and the risk of fire.

\section{Acknowledgements}

This study was supported by Structural Safety Matching Technology based on Fire Protection performance of Materials.

\section{Reference}

1. A. Ding, J. Wang, A. Ni, and S. Li, Compos. Struct. 202, 253-260 (2018)

2. Z. Jiang, K. Yao, Z. Du, J. Xue, T. Tang, and W. Liu, Compos. Sci. Technol. 97, 74-80 (2014)

3. Z. Jiang, K. Yao, Z. Du, J. Xue, T. Tang, and W. Liu, Compos. Sci. Technol. 97, 74-80 (2014)

4. Q. Zhang, Y. Yang, and L. Xiang, Polym. Test. 73, 418-424 (2019)

5. ASTM E. 2058-13, ASTM International, West Conshohocken, PA, (2013)

6. W. An, L. Jiang, J. Sun, and K. M. Liew, J. Therm. Anal. Calorim. 119, 229-238 (2014) 
7. Janssens ML. In: 2nd fire and material conference, interscience communication, 23-24 (1993)

8. Janssens M. Fire Master. 15, 151-67 (1991)

9. H. WANG, Journal of Safety and Environment, 18, 79-84 (2018)
10. X. Zhang, T. Zhang, T. Qiu, Z. Ding, C. Li, and S. Lu, Fire Technol. (2019)

11. R. Chen, S. Lu, C. Li, Y. Ding, B. Zhang, and S. Lo, J. Therm. Anal. Calorim. 123, 545-556 (2015)

12. U. Wickstrom and U. Goransson, J. Test. Eval. 15, 364-370 (1987) 